\title{
Regeneração óssea guiada em região estética da maxila: relato de caso
}

Guided bone regeneration in the aesthetic region of the jaw: case report

Regeneración ósea guiada en la región estética de la mandíbula: reporte de caso

Luís Henrique MICHELON

Graduando do Curso de Odontologia do Centro Universitário da Serra Gaúcha - FSG 95020-472 Caxias do Sul, Rio Grande do Sul, Brasil https://orcid.org/0000-0001-8635-1423

Lucas Bozzetti PIGOZZI

Professor Mestre da disciplina de Estágio em Prótese Dentária do Centro Universitário da Serra Gaúcha - FSG, $95020-472$ Caxias do Sul, Rio Grande do Sul, Brasil https://orcid.org/0000-0003-0368-8149

Alexandre CONDE

Professor Doutor da Disciplina de Prótese Total I e Il do Centro Universitário da Serra Gaúcha - FSG, 95020-472 Caxias do Sul, Rio Grande do Sul, Brasil https://orcid.org/0000-0003-0224-2313

Marília PAULUS

Professora Doutora da Disciplina de Estágio em Prótese Dentária do Centro Universitário da Serra Gaúcha - FSG, 95020-472

Caxias do Sul, Rio Grande do Sul, Brasil https://orcid.org/0000-0002-2615-5284

Mariá Cortina BELLAN

Professora Doutora da Disciplina de Estágio em Prótese Dentária do Centro Universitário da Serra Gaúcha - FSG, $95020-472$

Caxias do Sul, Rio Grande do Sul, Brasil https://orcid.org/0000-0002-7074-3518

Felipe SPINELLI

Cirurgião-Dentista formado pela Universidade de Passo Fundo - RS e Especialista em Implantodontia pela ABORS Guilherme FRANÇA

Graduando do Curso de Odontologia do Centro Universitário da Serra Gaúcha - FSG 95020-472 Caxias do Sul, Rio Grande do Sul, Brasil

\section{Resumo}

Introdução: A reabilitação com implantes nem sempre é possível devido à falta de quantidade óssea suficiente nos rebordos alveolares, o que acaba sendo um grande problema na recuperação estético-funcional dos pacientes. Diante disso, a Regeneração Óssea Guiada surge como uma ótima técnica para proporcionar aumento de volume ósseo e permitir a instalação de implantes. Objetivo: Descrever um relato de caso de uma cirurgia com a utilização da Regeneração Ossea Guiada com enxerto ósseo heterógeno bovino e auxílio de membrana reabsorvível para posterior colocação de implantes. Materiais e métodos: Para a avaliação do ganho de espessura óssea obtida com essa técnica, procedeu-se a comparação das tomografias computadorizadas de feixe cônico realizadas antes e após 6 meses da cirurgia para reabilitação com quatro implantes. Resultados: Na avaliação tomográfica, evidenciou-se um aumento de espessura óssea na região que variam de $1,5 \mathrm{~mm}$ a $4 \mathrm{~mm}$ em determinadas áreas, possibilitando a reabilitação com implantes dentários. Conclusão: O enxerto heterógeno bovino utilizado com a técnica de Regeneração Óssea Guiada tem apresentado uma grande capacidade de promover aumento ósseo, além de apresentar grau de reabsorção dentro dos limites para instalação dos implantes. Ademais, este tipo de enxerto traz um maior conforto ao paciente, já que elimina a necessidade de um segundo ato cirúrgico, sendo, portanto, mais uma opção de tratamento em casos de defeitos ósseos horizontais em região anterior de maxila.

Descritores: Osseointegração; Enxerto Ósseo; Materiais Biocompatíveis.

\section{Abstract}

Introduction: Rehabilitation with implants is not always possible due to the lack of sufficient bone in the alveolar edges, which ends up being a major problem in the aesthetic-functional recovery of patients. Given this, Guided Bone Regeneration appears as a great technique to provide increased bone volume and allow the installation of implants. Objective: To describe a case report of a surgery using Guided Bone Regeneration with a heterogeneous bovine bone graft and the aid of an absorbable membrane for subsequent implant placement Materials and methods: To assess the bone thickness gain obtained with this technique, we compared the cone beam computed tomography performed before and after 6 months of the procedure of rehabilitation with four implants. Results: In the tomographic evaluation, there was an increase in bone thickness in the region ranging from $1.5 \mathrm{~mm}$ to $4 \mathrm{~mm}$ in certain areas, enabling rehabilitation with dental implants. Conclusion: The heterogeneous bovine graft used with the Guided Bone Regeneration technique has shown a great capacity to promote bone augmentation, in addition to presenting a degree of resorption within the limits for implant installation. In addition, this type of graft brings greater comfort to the patient, since it eliminates the need for a second surgical act, being, therefore, another treatment option in cases of horizontal bone defects in the anterior region of the maxilla.

Descriptors: Osseointegration; Bone Transplantation; Biocompatible Biomaterials.

\section{Resumen}

Introducción: La rehabilitación con implantes no siempre es posible debido a la falta de suficiente hueso en los bordes alveolares, lo que acaba siendo un gran problema en la recuperación estético-funcional de los pacientes. Ante esto, la Regeneración Ósea Guiada aparece como una gran técnica para proporcionar un mayor volumen óseo y permitir la instalación de implantes. Objetivo: Describir el caso clínico de una cirugía mediante Regeneración Ósea Guiada con injerto óseo bovino heterogéneo y ayuda de una membrana absorbible para la posterior colocación del implante. Materiales y métodos: Para evaluar el aumento de espesor óseo obtenido con esta técnica, comparamos la tomografía computarizada de haz cónico realizada antes y después de 6 meses del procedimiento. Resultados: En la evaluación con la tomografía se evidenció un aumento del grosor óseo en la región que varió de $1,5 \mathrm{~mm}$ a $4 \mathrm{~mm}$ en determinadas zonas, lo que permitió la rehabilitación con implantes dentales. Conclusión: El injerto bovino heterogéneo utilizado con la técnica de Regeneración Ósea Guiada ha demostrado una gran capacidad para promover el aumento óseo, además de presentar un grado de reabsorción dentro de los límites para la instalación del implante. Además, este tipo de injerto aporta una mayor comodidad al paciente, ya que elimina la necesidad de un segundo acto quirúrgico, siendo, por tanto, otra opción de tratamiento en casos de defectos óseos horizontales en la región anterior del maxilar.

Descriptores: Oseointegración; Trasplante Óseo; Materiales Biocompatibles.

INTRODUÇÃO

O osso é um tecido conjuntivo
especializado, vascularizado e dinâmico que se modifica ao longo da vida do organismo.
Entretanto, quando uma lesão ocorre, ele possui uma capacidade única de regeneração e reparação sem a presença de cicatrizes. Já em grandes defeitos ósseos, o tecido duro não 
consegue se regenerar por completo ${ }^{1}$. Este problema se acentua em pacientes com grandes áreas edêntulas e com avançada reabsorção óssea alveolar, representando um grande desafio ao cirurgião-dentista no seu tratamento ${ }^{2}$.

Caso nenhum tratamento para restaurar a dentição seja providenciado, a perda óssea chegará a até $60 \%$ nos três primeiros anos, fazendo com que a colocação de implantes dentários possa ser inviabilizada em um primeiro momento, devido às dificuldades cirúrgicas e limitações anatômicas ${ }^{3}$. Portanto, com o intuito de minimizar essas perdas e capacitar a reabilitação de pacientes edêntulos, os implantes osseointegrados tem revolucionado a odontologia e melhorado a qualidade de vida destes pacientes. Para alcançar um bom e duradouro prognóstico, uma quantidade suficiente de osso deve existir no local a ser reabilitado ${ }^{3}$.

Por conta disso, diferentes estratégias como técnicas de enxerto ósseo, distração alveolar e Regeneração Óssea Guiada (ROG) têm sido aplicadas para restituir o osso perdido e permitir que o implante seja totalmente integrado e funcional ${ }^{4}$. Para realizar essas técnicas, existem uma gama de enxertos ósseos que podem ser utilizados, como os autógenos, homógenos, heterógenos e aloplásticos ${ }^{5}$.

Apesar dos enxertos ósseos autógenos serem aceitos como "padrão ouro" para o tratamento de defeitos ósseos, os enxertos homógenos e heterógenos, e os substitutos ósseos sintéticos têm sido amplamente estudados como uma ótima alternativa5. Uma das vantagens do enxerto heterógeno é a não necessidade de um segundo sítio cirúrgico, permitindo assim, um menor tempo de cirurgia e uma menor morbidade ao paciente ${ }^{6}$. Além disso, o osso heterógeno apresentou boa estabilidade em longo prazo, ao compará-lo aos enxertos autógenos, devido as suas características de lenta reabsorção ${ }^{7}$.

Para auxiliar a técnica, muitas vezes, também, se faz necessária a utilização de mais um aparato, que são as membranas. Este material é utilizado para criar um espaço de crescimento de osteoblastos, o que é benéfico para a cicatrização do osso, enxerto e demais tecidos, funcionando como uma barreira e prevenindo que células epiteliais e tecido conjuntivo migrem para o local. Esta técnica é chamada de Regeneração Óssea Guiada (ROG) ${ }^{7}$.

Estas membranas são divididas em reabsorvíveis e não reabsorvíveis. Elas possuem algumas diferenças entre si, tais como maior tempo clínico quando se usa as membranas não reabsorvíveis, devido à necessidade de um segundo ato cirúrgico para a sua remoção. Já a principal complicação relativa às membranas reabsorvíveis é sua possível degradação antes do tempo desejado, atrapalhando no processo de neoformação óssea ${ }^{8}$.

Desta forma, devido à ampla difusão na literatura sobre 0 assunto e das diversas opiniões e opções de técnicas e de materiais, o presente estudo tem como objetivo realizar a descrição de um relato de caso de uma cirurgia com a utilização da técnica de enxerto ósseo heterógeno bovino com Regeneração Óssea Guiada com membrana reabsorvível, para posterior colocação de implantes, cuja paciente apresentava amplo defeito ósseo horizontal em região anterior de maxila e desejava não fazer mais uso de prótese parcial removível.

CASO CLÍNICO

Esta pesquisa caracterizou-se por ser um relato de caso clínico do tipo transversal e observacional. $O$ projeto encontra-se aprovado após a análise no Comitê De Ética Institucional do Centro Universitário da Serra Gaúcha sob o parecer de número 4.213.791. O estudo foi composto através da análise de casos de pacientes que necessitavam de reabilitação com implantes, porém apresentavam perda óssea que inviabilizava o tratamento, e, portanto, tinham como indicação a cirurgia de enxerto ósseo. Além disso, os pacientes tinham que apresentar saúde sistêmica favorável ao procedimento cirúrgico. Caso apresentassem quaisquer doenças sistêmicas, como diabetes e hipertensão descompensadas, ou fizessem uso de medicamentos como os da classe dos bifosfonatos, o paciente seria excluído da pesquisa. A seleção resultou em paciente do sexo feminino, 47 anos de idade, residente de Farroupilha-RS, que se encaixava nos critérios de inclusão do estudo. Apresentava como queixa principal a insatisfação com 0 uso de prótese parcial removível (Figuras 1 e 2 ), alegando que a mesma estava desadaptada e com estética desfavorável, devido principalmente aos dentes de acrílico da prótese, o que apresentava perda de brilho e intensa pigmentação com o tempo. Após realização de uma tomografia computadorizada de feixe cônico (Figuras 3 e 4), para avaliação do tamanho da largura e espessura óssea na região anterior de maxila, foi constatado que para a instalação e posterior osseointegração dos implantes, seria necessário o procedimento de enxertia óssea, pois nos cortes parassagitais 
números 49, 59 e 74 que serão os respectivos cortes de instalação de três implantes necessários para a confecção da prótese fixa múltipla, a largura óssea era insuficiente, variando em aproximadamente 2,69-2,92 mm; 2,17-2,72 $\mathrm{mm}$ e 2,11- 2,33 $\mathrm{mm}$ respectivamente.

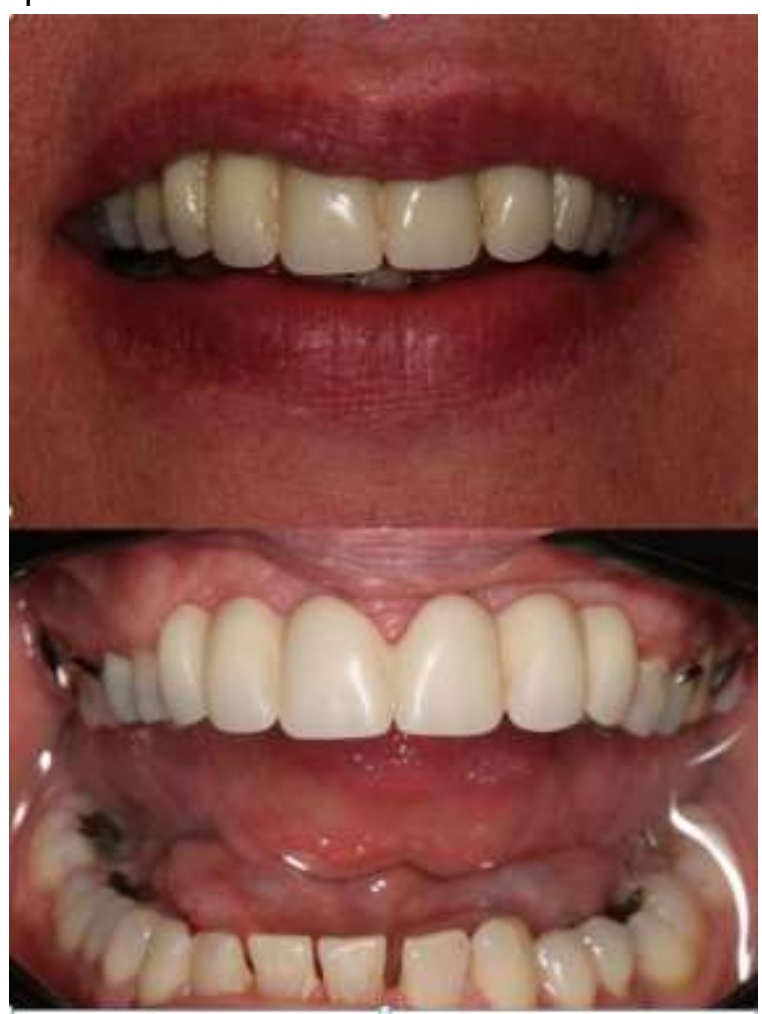

Figura 1: Vista vestibular da prótese parcial removível superior da qual a paciente relatava insatisfação com a estética, adaptação e o brilho dos dentes.

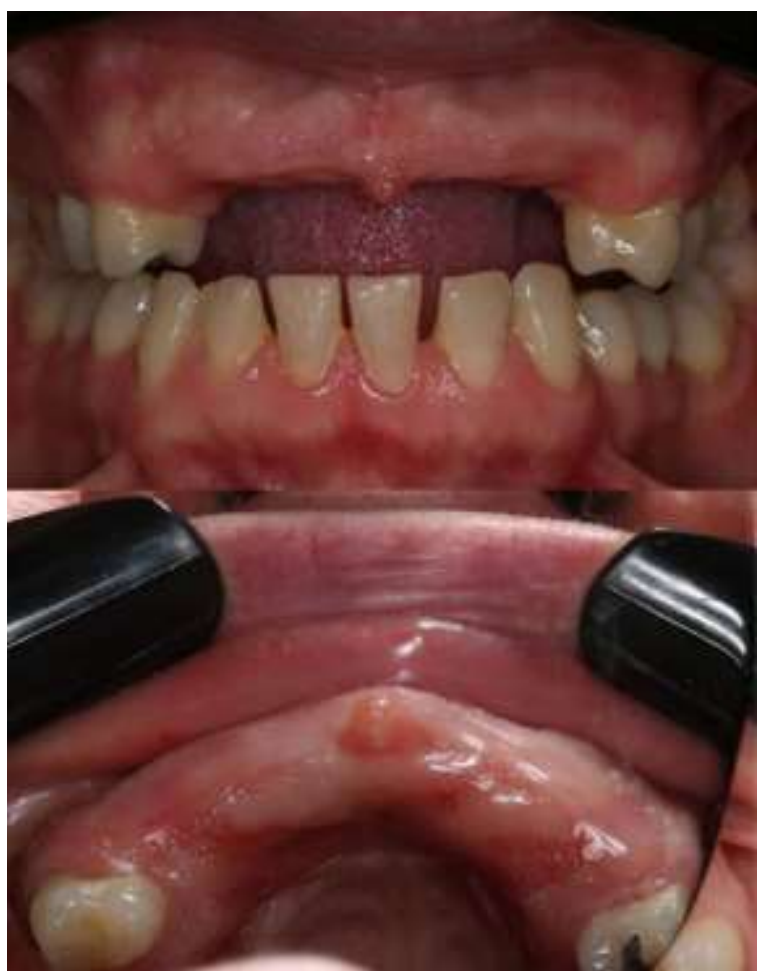

Figura 2. Vista vestibular e oclusal do rebordo alveolar da paciente. Nessas imagens já é possível perceber uma concavidade na região anterior superior, provocado pela perda óssea.

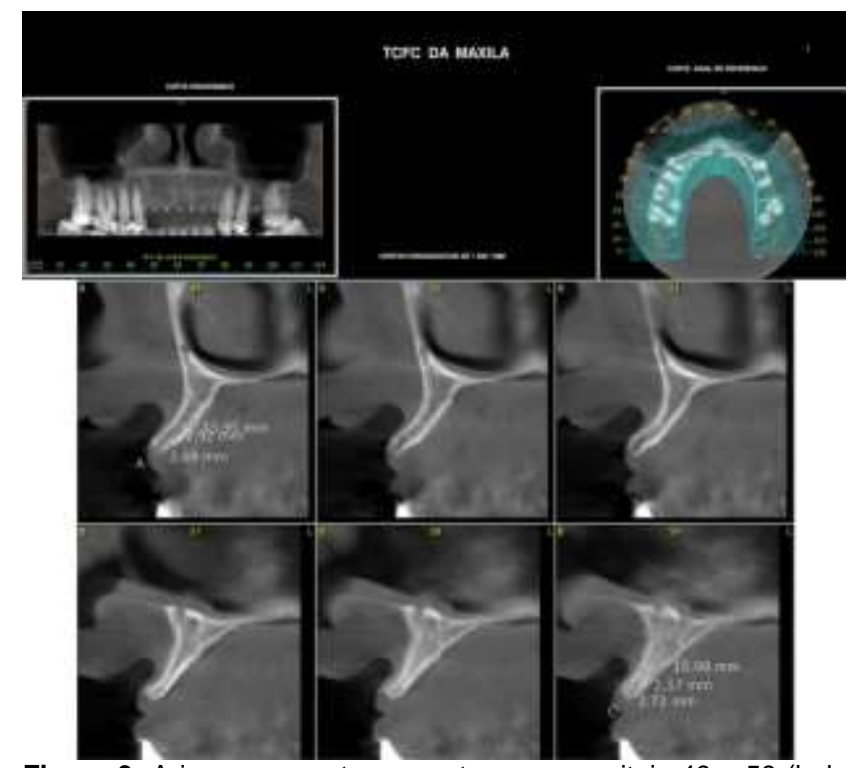

Figura 3: A imagem mostra os cortes parassagitais 49 e 59 (lado direito) retirados da tomografia computadorizada de feixe cônico, com as medidas da espessura óssea da paciente, que mostravase insuficiente para a instalação de implantes.

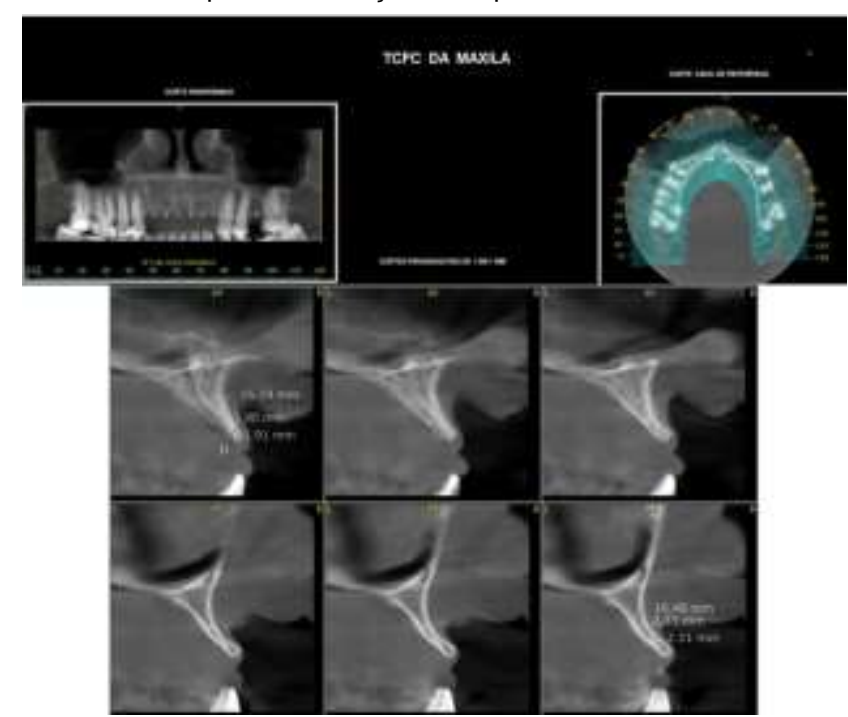

Figura 4: A imagem mostra alguns cortes parassagitais retirados da tomografia computadorizada de feixe cônico, com destaque para os de número 64 e 74 , que também evidenciam as medidas insuficientes de espessura óssea do lado esquerdo da paciente.

Durante o mês de julho, no ano de 2020, em uma clínica particular, situada na cidade de Farroupilha-RS, Brasil, foi realizada a cirurgia de Regeneração Óssea Guiada na região anterior da maxila com enxerto ósseo particulado heterógeno Straumann $\AA$ Cerabone ${ }^{\circledR}$ (Lotes: 19AA10450 e 19KA10560. Fabricação: Berlim, Alemanha) small e large misturados, com membrana reabsorvível Straumann $\AA$ Jason $\AA$ (Lote: 18JA51400. Fabricação: Berlim, Alemanha.) tamanho $30 \times 40 \mathrm{~mm}$, fixadas com 6 pinos de titânio (Figura 5) em um defeito ósseo horizontal que será reabilitado posteriormente com implantes. O procedimento, realizado por um cirurgião-dentista especialista em implantodontia e um cirurgião-dentista mestre e especialista em prótese dentária, seguiu todas as normas de biossegurança. Foi feita 
antissepsia com Digluconato de Clorexidina $2 \%$ na região extrabucal e $0,12 \%$ intrabucal. O sal anestésico utilizado foi Mepivacaína $2 \%$ com adrenalina 1:100.000, realizando anestesias tronculares no nervo alveolar superior anterior, infiltrativas em fundo de sulco e na região da incisão. A incisão foi realizada com lâmina de bisturi $\mathrm{n}^{\circ} \mathrm{0} 15$ contornando a sulco gengival vestibular, mesial e palatino dos primeiros prémolares superiores e sobre o rebordo anterior. Após isso, com o auxílio de um descolador de Molt, foi realizado o rebatimento do retalho mucoperiosteal que se apresentava bastante aderido e friável. Feito $o$ descolamento e exposição do tecido ósseo, foi instalada a membrana Jason com auxílio de quatro tachinhas de titânio WF Cirúrgicos® para a sua estabilização na região de fundo de sulco. Entre a membrana e o osso, foi colocado o enxerto ósseo particulado misturado e a membrana foi então assentada e estabilizada com mais duas tachinhas na região do palato.

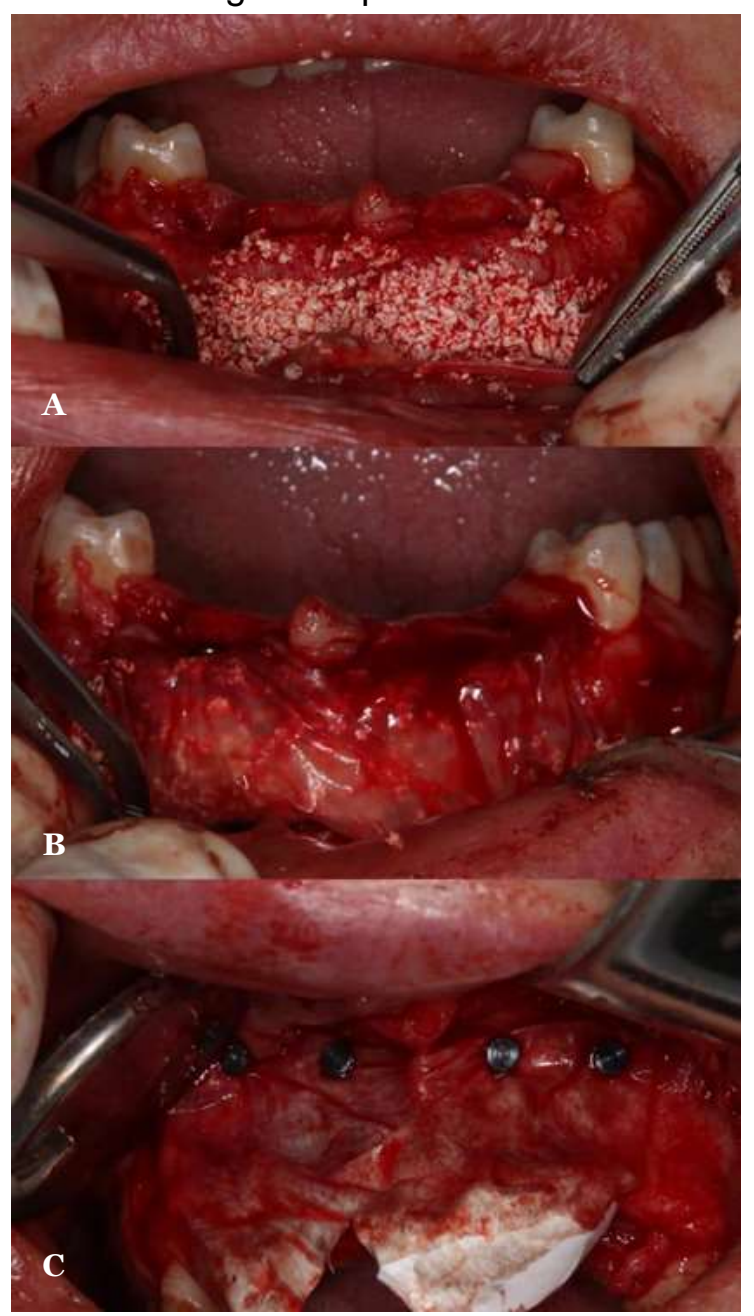

Figura 5: A. Colocação do enxerto ósseo heterógeno particulado sob o defeito ósseo. B. Membrana Reabsorvível envolvendo o enxerto ósseo. C. Fixação das seis tachinhas de titânio proporcionando maior estabilidade da membrana e do enxerto.

Sobre ela, foram suturados os retalhos com fio de Nylon 4-0 Ethicon In. $\AA$ em diversos pontos isolados até que a ferida estivesse com os bordos totalmente selados e sem sangramento ativo. A paciente recebeu orientações pós-operatórias como alimentação fria e pastosa nos primeiros dois dias, gelo na face, repouso e cuidados de higiene. Como medicação, foram prescritos Toragesic $\AA$, da farmacêutica EMS $\AA$, $10 \mathrm{mg}$ sublingual de $6 \mathrm{em}$ 6 horas por 3 dias, amoxicilina $500 \mathrm{mg}$ de $8 \mathrm{em}$ 8 horas por 7 dias e digluconato de clorexidina $0,12 \%$, com instruções para bochechar $15 \mathrm{ml}$ durante 1 minuto de 12 em 12 horas por 7 dias. A remoção da sutura foi feita após 7 dias. Observou-se uma fenestração na região vestibular, com exposição da membrana. Sucedeu-se então, a irrigação com soro fisiológico de maneira abundante semanalmente até fechamento completo da ferida. Após 6 meses do procedimento, foi realizada uma nova tomografia computadorizada de feixe cônico (conebeam), à fim de possibilitar a visualização da quantidade de espessura óssea que havia sido obtida com a Regeneração Óssea Guiada. Como é possível observar nos cortes parassagitais número 43, 49 e 54 (Figura 6), a largura óssea passou a ser de $3,90 \mathrm{~mm}, 3,69$ $\mathrm{mm}$ e $3,88 \mathrm{~mm}$ respectivamente, significando um aumento de $1,5 \mathrm{~mm}$ em algumas áreas. Já nos cortes parassagitais números 61, 66 e 72 (Figura 7), a espessura óssea passou a ser de $5,70 \mathrm{~mm}, 3,78 \mathrm{~mm}$ e $3,59 \mathrm{~mm}$, correspondendo a um aumento em determinadas áreas de quase $4 \mathrm{~mm}$. Com estas medidas, observou-se que para a colocação de implantes de $3.3 \mathrm{~mm}$ de diâmetro, algumas fenestrações de algumas roscas dos implantes poderão ocorrer, sendo esperadas no ato cirúrgico, devido à baixa espessura óssea inicial que a paciente apresentava.

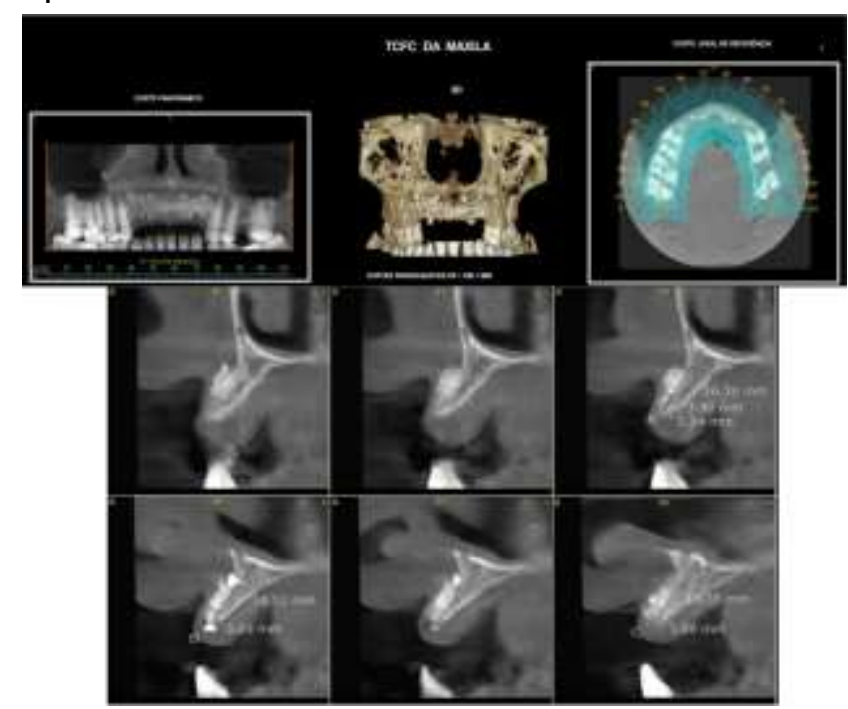

Figura 6: A imagem mostra alguns cortes parassagitais retirados da tomografia computadorizada de feixe cônico feita após o procedimento, com destaque para os de número 43,49 e 54 , que mostram um aumento da espessura óssea no lado direito e anterior da maxila da paciente. 


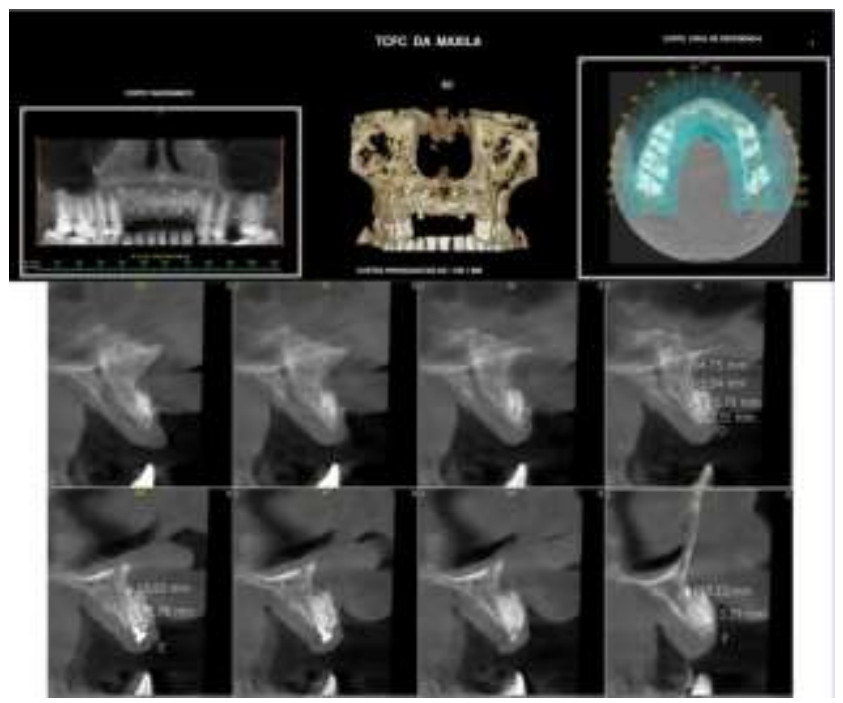

Figura 7: A imagem mostra alguns cortes parassagitais retirados da tomografia computadorizada de feixe cônico feita após 0 procedimento, com destaque para os de número 61,66 e 72 , que mostram um aumento da espessura óssea no lado esquerdo e anterior da maxila da paciente.

DISCUSSÃO

A utilização de enxerto ósseo bovino apresenta a capacidade de atuar como um arcabouço para a proliferação de células ósseas no hospedeiro, fazendo com que o osso nativo prolifere em ritmo contínuo e que com o tempo haja a substituição por osso neoformado ${ }^{9}$. Em uma revisão sistemática sobre aumento ósseo horizontal usando enxerto heterógeno, o mesmo utilizado neste estudo, reuniram-se 610 pacientes que foram submetidos a 853 procedimentos de enxertia óssea, envolvendo tanto a maxila quanto a mandíbula. Ao analisar todos os resultados, $94 \%$ dos procedimentos foram bem-sucedidos, com uma média de ganho de espessura óssea de $4,44 \mathrm{~mm}^{7}$, sendo essa suficiente para a colocação de implantes. Número que se assemelha com o presente estudo, que obteve áreas com aumento ósseo de $4 \mathrm{~mm}$.

Com isso, as indicações dos enxertos heterógenos vão desde pequenos defeitos do tipo fenestração ou deiscência (de até $4 \mathrm{~mm}$ ) a aumento de volume ósseo ${ }^{10}$, sendo, portanto, uma opção segura e eficaz para este caso.

No presente estudo, não foi possível medir a taxa de reabsorção do enxerto pela não realização de uma tomografia imediatamente após o procedimento cirúrgico, contudo, uma das principais vantagens dos enxertos heterógenos referem-se às taxas menores de reabsorção quando comparados aos enxertos autógenos $^{7}$. Para indicar a maior eficiência e segurança dos enxertos heterogêneos, um estudo mostrou que eles apresentam, em média, $24,4 \%$ de reabsorção. Enquanto os enxertos autogêneos mostraram taxas que variam de $10 \%$ a $49 \%$ de reabsorção ${ }^{7}$.
Outra importante característica dos enxertos heterógenos frente aos enxertos autógenos refere-se às menores complicações, que são recorrentes na remoção do osso autógeno, principalmente nas áreas de doação extraorais, devido à grande exposição cirúrgica, da necessidade de uma equipe multidisciplinar e de um ambiente hospitalar, custos elevados, pós-operatórios prolongados e maior sensibilidade nas regiões doadoras ${ }^{11}$. Este fator pôde ser observado no estudo, pois a paciente apresentou um pós-operatório mais curto e indolor, devido a não necessidade de uma segunda área cirúrgica.

Além disso, em busca de um melhor resultado, foram misturadas as partículas menores e maiores do enxerto ósseo. Os grânulos menores favorecem um melhor contorno de superfície, o que é excelente para regiões estéticas. $\mathrm{E}$ as partículas maiores proporcionam uma melhor revascularização em grandes defeitos ósseos, portanto uma mistura dos dois tipos é interessante em casos que há o desejo de recobrir uma extensa área em região anterior $^{12}$, assim como foi realizado neste estudo.

Contudo, para que a técnica de Regeneração Óssea Guiada possa ser executada, é imprescindível que existam materiais com o propósito de isolar os enxertos ósseos, funcionando como barreiras físicas para impedir a invasão das células gengivais e melhorar a qualidade do osso neoformado ${ }^{13}$. Por conta disso, observou-se a importância da criação de um tipo de membrana, que para ser funcional deve obedecer a alguns fatores determinantes, como: biocompatibilidade, a fim de permitir a integração nos tecidos do hospedeiro sem criar uma resposta inflamatória, propriedades físicas e mecânicas que acompanhem a neoformação de tecidos e, também, força suficiente para que não haja o seu colapso ${ }^{12}$. As membranas utilizadas no estudo foram as reabsorvíveis naturais à base de colágeno (Straumann®Jason®). Esse tipo de membrana tem como principal vantagem a capacidade de permitir procedimentos de um só passo, sem uma segunda cirurgia para a remoção, reduzindo 0 desconforto dos pacientes e os custos associados, evitando, também, as possíveis complicações cirúrgicas, comparando-se com as membranas nãoreabsorvíveis ${ }^{13}$. Elas também apresentam uma elevada biocompatibilidade, promoção de cicatrização e uma boa integração com o tecido conjuntivo (os osteoblastos e fibroblastos ligamse às membranas de colágeno, independente de sua origem bovina ou porcina) ${ }^{14}$. 
Outro material que foi utilizado em conjunto com as membranas são os pinos de titânio. Eles têm o papel de fixação das membranas, permitindo que um espaço seja mantido abaixo da membrana, sem que ela entre em colapso ou se desloque, garantindo que permaneça imóvel na posição desejada durante todo o tratamento, o que previne a migração do enxerto aos tecidos circundantes, evitando a perda das suas partículas ${ }^{15}$.

Porém, as membranas reabsorvíveis apresentam uma limitação que refere-se ao tempo de reabsorção e no efeito da degradação sobre a formação óssea, já que a degradação in vivo pode ser muito rápida em alguns casos, não mantendo a integridade estrutural pelo tempo necessário para a formação óssea que a ROG requer ${ }^{16}$. Esta intercorrência foi analisada neste estudo, onde após 5 dias do procedimento observou-se fenestração na região do enxerto e pequena exposição da membrana. Em uma pesquisa que reuniu 853 procedimentos com enxertos ósseos, encontrou-se uma taxa de complicações de $7,95 \%$, sendo a exposição de membrana o problema mais relatado ${ }^{7}$. Assim como na literatura comparada, não houve necessidade de intervenções cirúrgicas no presente estudo, sendo apenas feito irrigação no local com soro fisiológico durante 3 semanas até a cicatrização completa da região. Alguns autores recomendam profilaxia antibiótica por 7 dias e irrigação com clorexidina $0,12 \%{ }^{17}$.

Os procedimentos de Regeneração Óssea Guiada são dependentes de quatro princípios fundamentais: cicatrização por primeira intenção, angiogênese, manutenção do espaço e estabilidade do coágulo, e complicações em qualquer um desses princípios podem resultar em exposição prematura da membrana, levando a um potencial comprometimento do processo regenerativo da mesma. Para minimizar o risco dessas complicações, os autores alertam aos clínicos para avaliarem com atenção a quantidade de mucosa queratinizada, o biotipo tecidual, flexibilidade do retalho, o tipo e o tamanho do defeito ósseo e o tipo da membrana utilizada ${ }^{18}$.

Acredita-se que a intercorrência relatada no procedimento deveu-se à dificuldade em descolamento do tecido mucoso e submucoso e da fina espessura de mucosa queratinizada na região que a paciente apresentava. Caso seja necessária uma nova intervenção de ROG, poderá ser, portanto, indicada a realização de cirurgia de enxerto de tecido conjuntivo para ganho de volume tecidual.
Após a análise da segunda tomografia computadorizada conebeam, realizada posteriormente ao procedimento, constatou-se que para a instalação dos implantes previamente planejados de $3.3 \mathrm{~mm}$ de diâmetro, haveria o risco de fenestração de algumas roscas do implante. A fenestração óssea apresenta-se como um dos problemas anatômicos mais comuns encontrados na implantodontia, e geralmente ocorrem em rebordos alveolares com severa reabsorção óssea, comprometendo tanto a estética como a estabilidade mecânica dos implantes ali instalados $^{19}$. A ROG tem grande eficácia também no tratamento de fenestrações, já que as barreiras utilizadas impedem o contato dos tecidos periodontais com a superfície do implante, permitindo uma completa cicatrização óssea do local ${ }^{20}$.

O enxerto heterógeno bovino utilizado com a técnica de Regeneração Óssea Guiada mostrou grande capacidade de promover aumento ósseo, além de apresentar grau de reabsorção dentro dos limites aceitáveis para a instalação dos implantes, sendo, portanto, mais uma excelente opção de tratamento em casos de defeitos ósseos horizontais em região anterior de maxila ${ }^{7}$.

\section{REFERÊNCIAS}

1. Davies JE. Understanding peri-implant endosseous healing. J Dent Education. 2003; 67(8):49-53.

2. Jensen J, Sindet-Pedersen S. Autogenous mandibular bone grafts and osseointegrated implants for reconstruction of the severely atrophied maxilla: A preliminary report. Journal of Oral and Maxillofacial Surgery. 1991;49(12):1271-87.

3. Schropp L, Wenzel A, Kostopoulos L, Karring T. Bone healing and soft tissue contour changes following singletooth extraction: a clinical and radiographic 12 month prospective study. Int $\mathrm{J}$ Periodontics Restorative Dent. 2003;23(4): 13-23.

4. Elgali I, Omar O, Dahlin C, Thomsen P. Guided bone regeneration: materials and biological mechanisms revisited. Eur J Oral Sci. 2017; 125(5):315-37.

5. Fardin AC, Jardim EC, Pereira FC, Guskuma $\mathrm{MH}$, Aranega AM, Garcia IR. Enxerto ósseo em odontologia: revisão de literatura. Inno. Implant J Biomater Esthetics. 2010;5(3)48-52.

6. Gutierres M, Lopes MA, Hussain NS, Cabral AT, Almeida L, Santos JD. Substitutos Ósseos: conceitos gerais e estado atual. Arq Med. 2005; 19(4):153-62.

7. Carvalho PH, Trento GD, Moura L, Cunha G, Gabrielli MA, Pereira-Filho V. Horizontal ridge augmentation using xenogenous bone graft- 
systematic review. Oral Maxillofac Surg. 2019;23(3):271-79.

8. Greenstein G. Biodegradable barriers and guided tissue regeneration. Periodontology 2000. 1993;1(1):33-5.

9. Padovan LE, Silveira BM, Uhlendorf J, Uhlendorf Y, Corpas LS. Aplicabilidade dos enxertos em bloco de origem autógena e xenógena nas reconstruções ósseas: relato de caso clínico com avaliação tomográfica e histológica após seis meses. Implant News. 2014;11(2):176-13.

10. Souza SLS de, Oliveira RR de, Vidigal Júnior GM, Muglia VA, Souza AMMS, Novaes Júnior $A B$. Biomateriais na instalação de implantes osseointegrados. In: Periodontologia e implantodologia:soluções estéticas e recursos clínicos. Nova Odessa: Napaleão; 2010.

11. Rothamel D, Schwarz F, Herten M, Ferrari D, Mischkowski RA, Sager $M$ et al. Vertical ridge augmentation using xenogenous bone blocks: a histomorphometric study in dogs. Int $\mathrm{J}$ Oral Maxillofac Implants. 2009;24(2):243-50.

12. Miron RJ, Zhang Q, Sculean A, Buser D, Pippenger BE, Dard $\mathrm{M}$, et al. Osteoinductive potential of 4 commonly employed bone grafts. Clin Oral Investig. 2016;20(8):2259-65.

13. Bottino MC, Thomas V, Schmidt G, Vohra YK, Chu TM, Kowolik, MJ, et al. Recent advances in the development of GTR/GBR membranes for periodontal regeneration a materials perspective. Dent Mater. 2012;28(7):703-21.

14. Fontana E, Trisi P, Piatelli A. Freeze-dried dura mater for guided tissue regeneration in postextraction dental implants: A clinical and histologic study. J Peridontol. 1994;65(7): 658-65.

15. Wessing B, Lettner S, Zechner W. Guided Bone Regeneration with Collagen Membranes and Particulate Graft Materials: A Systematic Review and Meta-Analysis. Int J Oral Maxillofac Implants. 2018;33(1):87-100.

16. Dimitriou R, Mataliotakis GI, Calori GM, Giannoudis PV. The role of barrier membranes for guided bone regeneration and restoration of large bone defects: current experimental and clinical evidence. BMC Medicine. 2012;10,81.

17. Behring J, Junker R, Walboomers XF. Toward guided tissue and bone regeneration: morphology, attachment, proliferation, and migration of cells cultured on collagen barrier membranes. A systematic review. Odontology. 2008;96(1):1-11.

18. Garcia J, Dodge A, Luepke P, Wang HL, Kapila $\mathrm{Y}$, Lin GH. Effect of membrane exposure on guided bone regeneration: A systematic review and meta-analysis. Clin Oral Implants Res. 2018;29(3):328-38.
19. Calasans-Maia M, Fernandes G, Granjeiro J. Preservação alveolar com enxertos após exodontias e previamente à instalação de implantes. Implant News. 2008;5(6):583-90.

20. Resende, RFB, Calasans-Maia M, Schneltzer N, Granjeiro JM. Treatment of bone fenestration on immediate implants: case report. Implant News; 2010;7(1):54-9.

\section{CONFLITO DE INTERESSES}

Os autores declaram não haver conflitos de interesse

AUTOR PARA CORRESPONDÊNCIA

\section{Luís Henrique Michelon}

Rua Luiz Michielon, 566 (apto 41) - Bairro Cruzeiro Caxias do Sul, RS.

E-mail: luishenriquemichelon@gmail.com 